\title{
PREFACE
}

\section{Subclinical Communication Problems}

It has long been recognized by speechlanguage pathologists that the profession has a significant role in increasing "wellness" as well as ameliorating "illness" in their clients. This issue of Seminars in Speech and Language was prepared by individuals who firmly believe that speech-language pathologists should expand their role in the "wellness" arena. The contents of this issue may, at first, appear to challenge the traditional role and training of the speechlanguage pathologist. The challenge is there. However, it honors the traditional base while simultaneously recognizing that there exist information and research outside of the profession that can enrich and expand what speech- language pathologists can offer to their clients. More importantly, these articles reveal an increasing awareness in the profession of the importance of working with the "whole" client, not just the disorder. Finally, what is most exciting about these articles is that even though the articles were written by authors separated by geographical distance and professional experience, they have focused on several common themes, all of which emphasize working with "wellness" rather than "illness."

Lisa K. Breakey, M.A. Guest Editor ${ }^{1}$

Subclinical Communication Problems; Editors in Chief, Audrey L. Holland, Ph.D., and Nan Bernstein Ratner, Ed.D.; Guest Editor, Lisa K. Breakey, M.A. Seminars in Speech and Language, volume 26, number 2, 2005. ${ }^{1}$ Private Practice, San Jose, California. Copyright (C) 2005 by Thieme Medical Publishers, Inc., 333 Seventh Avenue, New York, NY 10001, USA. Tel: +1(212) 584-4662. 0734-0478,p;2005,26,02,105,105,ftx,en;ss100231b. 